\title{
SENYAWA NARINGENIN 7, 3', 4'-TRIMETIL ETER DARI DAUN TANAMAN PACAR CINA (AGLAIA ODORATA LOUR)
}

\author{
Dewi Kusrini, Soleh Kosela dan Chairul \\ Laboratorium Kimia Organikm Jurusan Kimia FMIP A-UNDIP, Kampus Tembalang Semarang
}

\begin{abstract}
Abstrak
Senyawa Naringenin, 7, 3', 4', - trimetil eter bethasil diisolasi dari fraksi n- heksana ekstrak daun Pacar cina. Senyawa tersebut diisolasi dengan cara kolom kromatografi $(\mathrm{KK})$ dan kromatografi cair kinerja tinggi (KCKT) serta ditentukan struktur molekulnya dengan menggunakan metode spektroskopi.
\end{abstract}

Kata kunct : naringenin, pacar cina, flavonoid. isolast, tdentifikast.

\section{Abstract}

\section{NARINGENIN 7, 3', 4'-TFIMETIL ETER FROM PACAR CINA'S LEAF}

Isolation and identification of bioactive compound of pacar cinas's leaf have been conducted by spectroscopy and chromatography method. Sample was extracted by n-hexane and separated by column chromatography using solvent gradient system (n-hexane, chloroform, ethyl acetate and methanol). Two fraction were purified by HPLC and resulting in two compound. The first compound was identified with IR spectroscopy. The result show that they were vibration of $\mathrm{OH}$, $>\mathrm{C}=\mathrm{O},>\mathrm{C}=\mathrm{C}<, \mathrm{CH} 3$ and $\mathrm{CH} 2$. MS spectroscopy gave its molecule weight 330,0885 . Beside that, the compound was also analyzed by $1 \mathrm{H}$ NMR and 13CNMR spectrum, it was conclude that compound is naringenin $-7,3^{\prime}, 4^{\prime}-$ try methyl ether.

Key word : naringenin, pacar cina, flavonotd, isolation, taentification.

\section{PENDAHULUAN}

Tanaman Pacar cina atau Aglaia odorata adalah tanaman yang termasuk dalam keluarga Meliaceae. Tanaman ini termasuk tanaman perdu, berasal dari Cina, juga termasuk tanaman obat tradisional, terutama daunnya digunakan sebagai obat kudis dan penolak serangga (Perry, 1980), juga rebusan daunya yang terasa pahit dapat digunakan sebagai pemampat menstruasi yang terus-menerus (blooding) (Heyne, 1978). 
Penelitian kandungan kimia dari daun tanaman pernah dilakukan oleh Shiengtong pada tahun 1977 yang berhasil mengisolasi semyawa aglaiol, pada tahun 1979 Shiengtong bersama Ungphakom berhasil mengisolasi senyawa odorine dan odorinol, selanjutrya Hayashi dkk (1982) berhasil mengisolasi senyawa odorinol ini, dan ternyata mempunyai aktivitas sebagai anti leukimia. Tanaman Pacar cina ( Aglaia odorata L) ini, tidak begitu dikenal di Indonesia, kerena umumrya harya digunakan sebagai hiasan pagar.

\section{Bahan Dan Percobaan}

Material bercobaan yaitu Aglaia odorata Lour, diperoleh secara acak dari berbagai pohon di daerah Bogor dan sudah dideterminasi di Herbarium Bogoriensis Bogor.

\section{Isolasi Dan Pemurnian}

Serbuk kering dari Pacar cina (Aglaia odorata) sebanyak $700 \mathrm{~g}$ dimaserasi selama satu malam dengan metanol ( $3 \times 3$ it ), filtratrya dipekatkan sehingga diperoleh ekstrak kasar sebanyak 85 g. Selanjutrya 80 g ekstrak kasar diekstraksi partisi dengan air + n-Heksana (1: 1) sebanyak 3 X $300 \mathrm{ml}$, kemudian dipisahkan dan dipekatkan maka diperoleh ekstrak n-Heksana sebanyak $11,23 \mathrm{~g}$.

Selanjutmya fraksi n-heksana dilakukan analisis kromatografi lapis tipis untuk mengetahui jumlah komponen yang terkancuung di dalam fraksi n-heksana, juga untuk memilih pelarut yang cocok yaitu campuran n-heksana : etil asetat $=8: 2$. fraksi n-heksana kemudian dianalisis kromatografi kolom dengan fase diam silikagel $60 \mathrm{G}$ dan fase bergerak campuran nheksana : etil asetat dengan kepolaran secara bertingkat. Fase-fase yang diperoleh yang mempunyai komponen dengan harga Rf yang sama disatukan dalam satu fraksi, pada fraksi yang ke 34-35 menjadi fraksi I terdapat 3 komponen, sedangkan fraksi yang ke 59-69 menjadi fraksi II terdapat 2 komponen. Selanjutnya fraksi II dimurnikan dengan kromatografi cair kinerja tinggi (KCKT) dengan kondisi kolom fasa norma' (Develosil $30-3,4,6 / 250$ ), Fase gerak n-heksana : etil asetat $=7: 3$. Diperoleh 2 komponen murni, A : $16,3 \mathrm{mg}$ dan B : $135 \mathrm{mg}$ ( bagan pemisahan).

Strukturmya ditentukan secara analisis fisika maupun spektroskopi. Titik leleh ditentukan dengan alat Fieser, spektnum infra merah (IR) diukur dalam bentuk pelet $\mathrm{KBr}$, spektrum massa (MS) dan kepastian spektrum massa (High Resolution Mass Spectrometer) dilakukan dengan alat Joel D 300 Spectrometer (voltase ionisasi $30 \mathrm{eV}$ ). 1 $\mathrm{H}$ dan ${ }^{13} \mathrm{C}-\mathrm{NMR}, \mathrm{C}-\mathrm{H}$ COSY dan $\mathrm{H}-\mathrm{H}$ COSY diperoleh dengan alat Varian Instrumen Ltd, spektrometer dengan larutan $\mathrm{CDCl}_{3}$ dengan TMS sebagai standar dalam pada $600 \mathrm{Mhz}(1 \mathrm{H})$ dan $50,3 \mathrm{Mhz}(13 \mathrm{C})$. Kromatografi Lapis Tipis (KLT) dilakukan pada plat silika gel $60 \mathrm{G}$ dan preaksi warna anisaldehid. Pada Kromatografi Kolom sebagai fase diam silika gel $60 \mathrm{G}$ dan fasa geraknya larutan campuran n-heksana : etil 
asetat dengan tingkat kepolaran secara bertahap, sedangkan untuk pemurnian digunakan Kromatografi Cair Kinerja Tinggi (KCKT) dengan kondisi kolom normal ( Develosil 30-3, 4,6/250) dan fase gerak nheksana : etil asetat ( $7: 3$ ). Larutan dipekatkan dengan evaporator (Vakum).

Komponen A : 5 -hidroksi, 7,3', 4' ,trimetoksi flavanon (Naringenin, 7, 3, , ${ }^{\prime}$,trimetil eter ) sebanyak $16,3 \mathrm{mg}$, kristal putih, mp 158-160 (C, $(\mathrm{M}+)$ pada $\mathrm{m} / \mathrm{z} 330,0885$ dihitung untuk numus molekul (formula) $\mathrm{Cl} 8$ H18 O6, 330, 3404.

IR Vmax $\mathrm{cm}^{-1} ; 3450,2950,1650,1510$, $1450,1430,1370,1300,820$ dan 780 .
HRMS pada $\mathrm{m} / \mathrm{z}$ (rel.int \%); $330(\mathrm{M}+$, $88), 313(6,6), 193(15,7), 164(72)$ dan 151 $(100)$.

${ }^{1}$ HNMR (600 Mhz, CDCl3 ) ( TMS ; 12,03 $(1 \mathrm{H}, \mathrm{s}), 6.99(1 \mathrm{H}, \mathrm{d}, \mathrm{J}=1 \mathrm{~Hz}), 6,98(1 \mathrm{H}$, dd, $\mathrm{J}=9$ dan $1 \mathrm{~Hz}), 6,92(1 \mathrm{H}, \mathrm{d}, \mathrm{J}=9 \mathrm{~Hz})$, $6.08(1 \mathrm{H}, \mathrm{d}, \mathrm{J}=2 \mathrm{~Hz}), 6,08(1 \mathrm{H}, \mathrm{d}, \mathrm{J}=$ $2 \mathrm{~Hz}), 5,39(1 \mathrm{H}, \mathrm{dd}, \mathrm{J}=12$ dan $3 \mathrm{~Hz}), 3,95$ $(3 \mathrm{H}, \mathrm{s}) 3,91(3 \mathrm{H}, \mathrm{s}), 3,81(3 \mathrm{H}, \mathrm{s}),, 3.13(3 \mathrm{H}$, dd, $\mathrm{J}=16$ dan $12 \mathrm{~Hz})$ dan $2,85(1 \mathrm{H}, \mathrm{dd}, \mathrm{J}=16$ dan $3 \mathrm{~Hz}$ ).

${ }^{13} \mathrm{C}-\mathrm{NMR}\left(\mathrm{CDCl}_{3}\right)$ (TMS ; 195,9 (s), 168,0 (s), 164,2 (s), 162,8 (s), 149,5 (s), 149,3 (s) 130,8 (s), 118,9 (d), 112,2 (d), 109,9 (d), 103,2 (s), 95,2 (d), 94,3 (d), 79,2 (d), $56,01 \quad(\mathrm{~s}, \mathrm{OMe}), \quad 56,01 \quad(\mathrm{~s}, \mathrm{OMe}), \quad 55,7$ (s,OMe) dan 43,35 (t).

\section{Bagan Pemisahan}

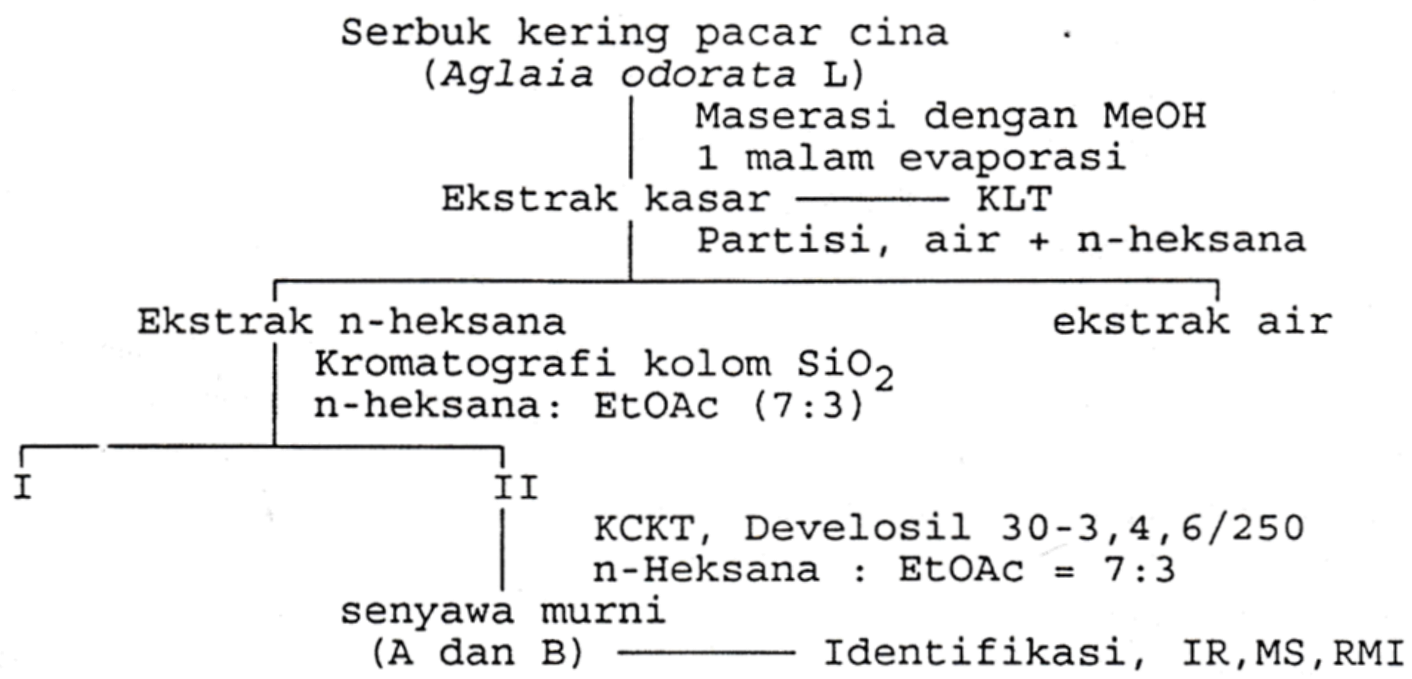




\section{Data alat KCKT}

Pompa : Shimadzu- LC - 6AD

Kolom : Develosil $30-3 \quad(4,6 / 250)$

Pelarut : n- Heksana : Etil Asetat $=7: 3$

Detektor : Shimadzu RID - 6A

Kec. Kertas : $1 \mathrm{~mm} / \mathrm{menit}$

Temperatur : nuang

\section{HASIL DAN PEMBAHASAN}

Hasil isolasi komponen murni (Pacar cina) dari ekstrak n-heksana dengan cara Kromatografi Kolom dan Kromatografi Cair Kinerja Tinggi (KCKT) salah saturya adalah komponen A, yang berbentuk kristal putih, mp $158-160$ (C. Spektrum Mssa memberikan ion molekul pada $\mathrm{m} / \mathrm{z} 330,0885$ dengan rumus molekul $\mathrm{C} 18 \mathrm{H} 18$ O6 (HRMS)dan teoritis 330, 140. Spektrum infra merah adarrya gugus hidroksil $(\mathrm{OH})$ ditunjukkan pada $3450 \mathrm{~cm}-1$, karbonil terkonyugasi ( $1650 \mathrm{~cm} \mathrm{-1})$, dan eter $(1300$ $\mathrm{cm} \mathrm{-1} \mathrm{).} \mathrm{Spektrum} \mathrm{-1} \mathrm{HNMR} \mathrm{(Gb.} \mathrm{1)} \mathrm{terlihat}$ adanya sinyal tunggal pada $(12,03 \quad(1 \mathrm{H}, \mathrm{s})$, menunjukkan adarya gugus hidroksi $(\mathrm{OH})$, pergeseran kimia yang sangat down field karena adanya ikatan hidrogen dengan gugus karbonil ( $\mathrm{C}=0$ ), simyal proton aromatik pada $\left(6,99\left(1 \mathrm{H}, \mathrm{d}, \mathrm{J}=1 \mathrm{~Hz}, \mathrm{H}-2^{\prime}\right),(6,98(1 \mathrm{H}\right.$, dd, $\mathrm{J}=9$ dan $\left.1 \mathrm{~Hz}, \mathrm{H}-6^{\prime}\right)$, dan $(6,92(1 \mathrm{H}, \mathrm{d}$, $\left.\mathrm{J}=9 \mathrm{~Hz}, \mathrm{H}-5^{\prime}\right)$ membentuk sistem $\mathrm{ABX}$ : $(\mathrm{HC}=\mathrm{CH}-\mathrm{CH}=\mathrm{C})$ tetapi tidak begitu sempurna. Sedangkan pada $(6,08(1 \mathrm{H}, \mathrm{d}, \mathrm{J}=$ $2 \mathrm{~Hz}, \mathrm{H}-6)$ dan $(6,07(1 \mathrm{H}, \mathrm{d}, \mathrm{J}=2 \mathrm{~Hz}, \mathrm{H}-8)$ merupakan interaksi jarak jauh (4 J), 3 sinyal tunggal dari gugus metoksi pada ( 3,92 $(3 \mathrm{H}, \mathrm{s})$, dan $(3,81 \quad(3 \mathrm{H}, \mathrm{s})$. Simyal yang membentuk sistem ABX ke 2 ( Atta-ur Rahman, 1989), dimana sinyal X pada $(5,4$
(1H, dd, $\mathrm{J}=12$ dan $3 \mathrm{~Hz}, \mathrm{H}-2 \mathrm{X}$ ) berinteraksi dengan sistem $A B$ yaitu 2 proton pada $(3,13$ $(1 \mathrm{H}, \mathrm{dd}, \mathrm{J}=16$ dan $12 \mathrm{~Hz}, \mathrm{H} 30$ dan ( $2,85(1 \mathrm{H}, \mathrm{dd}, \mathrm{J}=16$ dan $3 \mathrm{~Hz}, \mathrm{H}-30$ diperjelas dengan spektrum H-H COSY. Spektrum 13 C-NMR ( Gb. 2) menunjukkan adanya satu atom karbonil terkonyugasi pada ( 195, 9 (s), tujuh karbonil kuartener pada ( $168,0(\mathrm{~s}),(164,2(\mathrm{~s}),(162,8(\mathrm{~s}), \mathrm{d} 149,5(\mathrm{~s})$, (149,3 (s), 130,8 dan ( 103,2 (s). Lima karbon tersier pada (118, 9 (d), (112,2 (d), ( 95,2 (d) dan ( 94,3 (d), satu karbinol pada ( 79,2 (d), tiga gugus metoksi 2 diantaranya pada ( 56,01 (q, OMe) overlaping dan satu lagi pada $(55,7(q, \mathrm{OMe})$, sedang satu karbon metilen pada ( 43,35 (t).

\section{Spektrum C-H COSY (Gb.3)} memperlihatkan lebih jelas hubungan antara proton dan karbon, dimana proton pada ( 2,85 (A) dan ( 3,13 (B) berinteraksi dengan atom karbon yang sama pada ( 43,4 (t), proton dari gugus metoksi pada $(3,81$ terikat atom karbon pada ( 55,7 (q) sedangkan pada ( 3,91 dan ( 3,92 terikat pada atom karbon yang sama yaitu pada ( 56,01 (q), simyal proton pada $(5,4(\mathrm{X})$ mempuryai interaksi dengan atom karbon pada ( 79,2 (d), dua proton aromatik pada ( 6,08 dan $(6,07$ berinteraksi dengan atom karbon pada ( 94,3 (d) dan 95,2 (d), sedangkan tiga atom karbon aromatik yang lain pada ( 6,99 berinteraksi dengan atom karhon pada ( 109,5 (d), ( 6,98 dengan atom karbon pada ( 118,9 (d) dan (6,92 berinteraksi dengan atom karbon pada (111,2 (d). Pada spektrum H-H COSY, mempertihatkan lebih jelas hubungan proton satu dengan lainnya ( $\mathrm{Gb} .4$ ), proton pada $(2,85$ berinteraksi dengan proton pada $(3,13$ 
dan ( 5,4 dengan membentuk sistim $\mathrm{ABX}$, sedangkan proton pada $(6,92$ berinteraksi dengan proton pada $(6,98$ dan ( 6,99 yang membentuk sistim $A B X$ yang ke dua. Dalam percobaan HMBC (Gb. 5), memperlihatkan lebih jelas hubungan antara satu proton dengan atom karbon yang berdekatandengan jarak 2 sampai 3 atom karbon. Spektrum menunjukkan sinyal proton $\mathrm{AB}(2,85)$ dan $(3,13)$ terletak pada posisi yang berdekatan dengan atom karbonil pada ( $1,95,9$ (s), satu gugus metoksi terletak berdekatan dengan atom karbon kuartener pada ( 168,0 (s), dua gugus metoksi yang lain terletak berdekatan dengan karbon kuartener pada ( 149,3 (s) dan 149,5 (s). Gugus hidroksi (OH) terletak berdekatan dengan karbon kuartener pada ( 164,2 (s), ( 103,2 (s) dan karbon tersier pada ( 95,2 (d). Proton X (( 5,4) berdampingan dengan karbon kuartetner pada ( 130,8 ( C-1 ), juga berdekatan dengan karbon tersier pada ( 109,5 (d) dan ( 118,9 (d). Dua proton aromatik paada ( 6,08 berdekatan dengan karbon kuartener pada ( 168,0 (s) dan ( 164,2 (s), sedangkan pada ( 6,07 berdekatan dengan karbon kuartener pada ( 168,0 (s) dan (162,8 (s). Dari hasil analisis data spektroskopi dapat ditentukan bahwa senyawa yang didapat sebagai Naringenin, 7, 3', 4' - trimetil eter [ Shrivastava, 1982 ( 5-hidroksi , 7, 3', 4', trimetoksi flavonon )], strukturnya dapat digambarkan beserta ringkasan percobaan HMBC.

Senyawa flavonoid ini pertama kali diisolasi dari daun Pacar cina ( Aglaia odorata L). Banyak sekali senyawa flavonoid yang hampir mirip dengan Naringenin ini, yang sudah diketemukan seperti pada Lauraceae,
Compositae ( Shimomura, 1988; Marco; 1988; Raitman, 1985 ).

\section{KESIMPULAN DAN SARAN}

Hasil isolasi dan pemurnian dari daun Pacar cina pada ekstrak n- heksana diperoleh beberapa senyawa murni, salah satumya adalah senyawa flavonoid yaitu: Naringenin, 7, 3', 4' -trimetil eter. Seperti telah diketahui bahwa Naringenin, 7, 3, 4', - trimetil eter terdapat pada tanaman obat, tetapi khasiat dan aktivitasnya behm lagi terungkap. Sebagai tindak lanjut perlu dilakukan penelitian untuk mengetahui khasiat dan aktivitasnya.

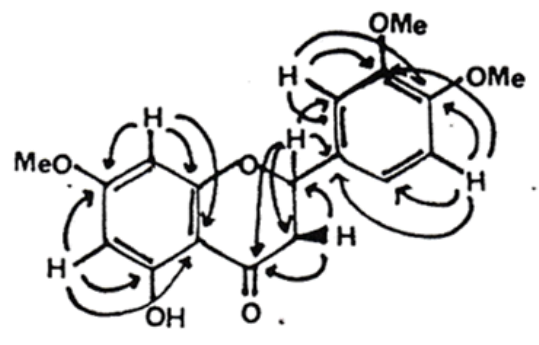

Struktur dan ringkasan HMBC dari senyawa naringenin- $7,3^{\prime}, 4^{\prime}$, - trimetil eter.

\section{Daftar Pustaka}

Atta - ur Rahman, 1989, Nuclear Magnetic Resonance Spectroscopy, National Academy of Higher Education University Grants Commission H-9, Islamabad, Vol. I, 46-51.

Hayashi. N., Kuo, H.L., and Hall, I.H., (1982), Phytochemistry, 21, 2371-2373. 
Hayne, K., (1987), Tumbuhan berguna Indonesia, Bidang Litbang Kehutanan Jakarta. Jilid II, 1130-1131.

Marco, A.J., and Barbera, O., (1988), Phytochemistry, 27 (10), 3315-3159.

Perry, L.M., (1980), Medicinal Plant of East and Southeast asia, The MIT Prees, Cambridge, Massechussetts and London, 260.

Roitman, J.N., and James, L.F., (1985),

Phytochemistri, 24 (4), 835-848.
Shiengtong, D., (1977), J. Chem, Soc. Perkin Trans, I (5) 510-512.

Shiengtong, D., and Ungphakorn, A., (1979), Tetrahedron Letters, 24, 2247-2250.

Shimomura, H., (1988), Phytochemistry, 27 (12) 3937-3939.

Shrivastava, S.P., (1982), Phytochemistry, 21 (6)1464-1465. 